\title{
Análise comparativa da retração por secagem de concretos com fibras novas e recicladas de poliéster
}

\author{
Comparative analysis of the retraction through the drying \\ shrinkage of new and recycled polyester fibers
}

\section{Hinoel Zamis Ehrenbring \\ Bernardo Fonseca Tutikian \\ Uziel Cavalcanti de Medeiros Quinino}

\section{Resumo \\ A}

nalisando as características físicas das matrizes cimentícias, é possível destacar a retração como uma das mais influentes nos quesitos de durabilidade do material. Caso não seja previsto ou controlado, esse fenômeno tem potencial de causar graves problemas em sistemas, tal como a nucleação de fissuras. Devido ao efeito de retração da matriz, quando restringida, é inevitável deparar-se com a formação de fissuras nas idades iniciais do concreto em virtude do fenômeno da sua variação volumétrica. Sabe-se que a adição de fibras, respeitando a compatibilidade de dimensões entre os materiais constituintes e o teor adequado desse reforço, afeta as propriedades do compósito resultante, diminuindo seu potencial de fissuração. Nesse sentido, esta investigação avalia os efeitos causados pela inserção de fibras de poliéster novas e usadas na retração por secagem de concretos. Os resultados de resistência à compressão não sofreram alterações com a adição das fibras de poliéster no concreto de referência. Por meio do ensaio de anel restringido foi possível constatar ganhos de eficiência nas misturas com o uso de fibras, quando se refere à retração por secagem restringida da matriz de referência. As tensões de retração por secagem são aumentadas cerca de duas vezes com a inclusão dos reforços fibrosos. Pôde-se observar que a adição de fibras recicladas de poliéster proporcionou redução, cerca de $80 \%$, na formação de fissuras na matriz quando comparada aos efeitos de reforço em concretos com adição das fibras virgens.

Palavras-chave: Concreto com fibra. Retração por secagem. Fibras de poliéster. Potencial de fissuração.

Hinoel Zamis Ehrenbring itt Performance Universidade do Vale do Rio dos Sinos São Leopoldo - RS - Brasil

Bernardo Fonseca Tutikian itt Performance Universidade do Vale do Rio dos Sinos São Leopoldo - RS - Brasil

Uziel Cavalcanti de Medeiros

Quinino itt Performance Universidade do Vale do Rio dos Sinos São Leopoldo - RS - Brasil

Recebido em 03/03/17 Aceito em 16/09/17

\section{Abstract}

Analyzing the physical characteristics of the cementitious matrices, it is possible to highlight the shrinkage as one of the most influential in the durability. If not predicted or controlled, this has the potential to cause serious problems in systems, such as cracking. Due to the shrinkage effect of the matrix it is inevitable to encounter cracks in the early ages of the concrete due to the phenomenon of their volumetric variation. It is known that the addition of fibers affects the properties of the resulting composite, reducing its cracking potential. In this sense, this research evaluates the effects caused by the insertion of new and used polyester fibers in the drying retraction of concretes. The results of the compressive strength did not change with the addition of the polyester fibers in the reference concrete. By means of the restricted ring test it was possible to observe efficiency gains in the blends with the use of fibers, when it refers to the retraction by means of the reference matrix. The shrinkage stresses on drying were increased about twice with the inclusion of the fibrous reinforcements. It could be observed that the addition of recycled polyester fibers provided a reduction, about $80 \%$, in the formation of cracks in the matrix when compared to the reinforcing effects in concrete with addition of the virgin fibers.

Keywords: Fiber reinforced concrete. Drying shrinkage. Polyester fibers. Cracking potential.

EHRENBRING, H. Z.; TUTIKIAN, B. F.; QUININO, U. C. de M. Análise comparativa da retração por secagem de concretos 195 com fibras novas e recicladas de poliéster. Ambiente Construído, Porto Alegre, v. 18, n. 3, p. 195-209, jul./ set. 2018. ISSN 1678-8621 Associação Nacional de Tecnologia do Ambiente Construído.

http:// dx. doi. org/ 10.1590/ s1678-86212018000300276 


\section{Introdução}

Amplamente utilizado na construção civil, o concreto é um dos materiais mais versáteis para a confecção de sistemas estruturais da atualidade (NEVILLE; BROOKS, 2013). Para Goodier (2003) e Quinino (2015), o concreto é formado a partir da mistura estratégica de outros materiais, e suas propriedades finais resultam das características de interação de cada um desses elementos de constituição. Uma matriz cimentícia dosada de maneira adequada é capaz de apresentar propriedades mecânicas elevadas, como resistência à compressão e módulo de elasticidade. Além desses, a durabilidade do compósito também é um fator interessante na sua caracterização (MEHTA; MONTEIRO, 2014).

Porém, devido a sua heterogeneidade, o concreto possui baixa resistência à tração, cerca de $10 \%$ da resistência à compressão, e tem ruptura frágil (DESNERCK; LEES; MORLEY, 2015; YU et al., 2016). Com isso, faz-se necessária a inserção de reforços nessas matrizes cimentícias a fim de evitar a ruptura prematura do elemento, mitigar a nucleação de fissuras, aumentar sua capacidade de carga, modificar a energia de ruptura e acrescer durabilidade (TASK, 2000; ALKAYSI et al., 2015; IBRAHIM et al., 2017). Nesse caso, o uso de reforços tem potencial de mitigar ou amenizar consequências geradas pelas características inerentes às matrizes cimentícias, sendo uma delas a fissuração devido à retração por secagem (SENISSE, 2010; GU; YE; SUN, 2015).

A retração em concretos pode ser dividida em diferentes tipos, como plástica, autógena, por carbonatação e por secagem (MAZZOLI; MONOSI; PLESCIA, 2015). Vale salientar que esse fenômeno físico-químico é representado pela variação volumétrica do material causada pela perda e consumo de água da pasta de cimento (KAUFMANN; WINNEFELD; HESSELBARTH, 2004; NUNES; FIGUEIREDO, 2007; MEHTA; MONTEIRO, 2014). No caso da retração por secagem, o consumo de água para hidratação do cimento anidro é fator potencializador desse tipo de fenômeno (KURDOWSKI, 2014; SENISSE, 2015). Segundo Wittmann, Beltzung e Zhao (2009), a retração por secagem é a origem mais frequente na formação de fissuras em matrizes cimentícias.

O processo de formação de fissuras em concretos se dá por diferentes razões, podendo ser provenientes das restrições de movimentação, por vezes causando aumento de esforços internos de tração na mistura (CARINO; CLIFTON, 1995). Assim, a nucleação de fissuras, mesmo com dimensões minoradas, é responsável pela redução na durabilidade do sistema devido à facilitação na entrada de agentes agressivos, como os íons cloreto e dióxido de carbono (CARMONA FILHO; CARMONA, 2013). Além dos fatores mencionados, o aumento das solicitações internas também é um agravante ao concreto sem reforço (ZHANG; ZAKARIA; HAMA, 2013). Com isso, quando essas tensões excedem a resistência à tração do material, há ruptura da matriz (DJERBI; BONNET; KHELIDJ, 2008; ZACHARY; MATTHEW, 2011).

O combate ao surgimento de fissuras pode ser feito de diversas maneiras em um composto cimentício (ABABNEH, 2001; YIN et al., 2015; JUAREZ et al., 2015). O uso de fibras se tornou um procedimento eficaz de reforço, com o intuito de superar as limitações de resistência à tração e aspecto frágil dos concretos convencionais (CHASIOTI; VECCHIO, 2017). O concreto reforçado com fibras (CRF) pode apresentar melhorias evidentes quando comparado aos concretos convencionais, pois a inserção de filamentos eleva a tenacidade e a resistência à fissuração, proporciona uma pseudoductilidade ao compósito (JAMERAN et al., 2015). Entretanto, as características alteradas nas misturas variam a partir do material que constitui a fibra e suas dimensões (NEVILLE, 1997; OSTERTAG; BLUNT, 2010).

Alguns fatores estão atrelados aos comportamentos resultantes de um concreto reforçado com fibras. Como foi visto, as propriedades e o tipo de reforços a serem utilizados são de extrema importância. Outro fator pertinente é o teor de adição do material. O tipo de matriz que será reforçada pode alterar por completo o processo de dosagem de um compósito com fibras (BENTUR; MINDESS, 2007). A adição de fibras na matriz é feita de modo que ocorram melhorias nas propriedades do produto. Porém, o ganho de desempenho acontece quando a interação fibra-matriz é eficaz, proporcionando a transferência dos esforços da matriz ao reforço (BERNARDI, 2003; BENTUR; MINDESS, 2007; QUININO, 2015).

Nos últimos anos publicaram-se diversas pesquisas ilustrando o potencial de diferentes filamentos quando adicionados no concreto. Têm-se como exemplo as fibras de aço, polipropileno, vidro e também fibras de poliéster (PELISSER et al., 2012). Segundo Ghugal e Naghate (2016), os reforços poliméricos, como os de poliéster, ganham destaque na indústria da construção civil quando aplicados em concretos e argamassas. Porém, sua inserção é limitada devido ao baixo módulo de elasticidade do material (OCHI; OKUBO; FUKUI, 2007). Dessa maneira, o uso de fibras de poliéster em concretos pode ser deslocado para combate na 
nucleação e propagação de fissuras por retração, mostrando bons resultados (GHUGAL; NAGHATE, 2016).

Fibras de baixo módulo de elasticidade, como aramida, polipropileno e poliéster, não são recomendadas para matrizes com funções estruturais, pois o módulo de elasticidade do composto supera o do filamento, fazendo com que a fibra atue somente nos efeitos de segunda ordem (TANESI; FIGUEIREDO, 1999; YIN et al., 2015; YOUSEFIEH et al., 2017). Além disso, o período de atuação efetiva dos filamentos de baixo módulo de elasticidade permanece nas idades iniciais da mistura (SILVA, 2007). Dessa maneira, para que se obtenha um compósito com propriedades mecânicas melhoradas e elevada durabilidade, Ghugal e Naghate (2016) recomendam o uso de fibras poliméricas (poliéster) hibridizadas às de aço.

De acordo com Boghossian e Wegner (2008) e Quinino (2015), a adição de algumas fibras, como de aço, acima de $1 \%$ do volume da matriz aumenta expressivamente $\mathrm{o}$ fator de tenacidade e a resistência à tração da matriz. Já teores entre $0,1 \%$ e $0,3 \%$ de reforços poliméricos e naturais auxiliam a contenção de fissuras por retração da pasta de cimento hidratada (BRAS et al., 2013).

Com isso, o trabalho direciona-se à determinação do potencial de fibras novas e recicladas de poliéster quando adicionadas no concreto em função da retração por secagem do compósito. Comprovando o bom desempenho dessas fibras na retração do concreto, é possível aprimorá-las de modo a disponibilizá-las ao mercado da construção civil com o intuito de diminuir o impacto ambiental e tornar o sistema com fibras de poliéster mais atrativo do ponto de vista funcional e econômico.

\section{Programa experimental}

A seção a seguir apresenta os materiais e os métodos de instrumentação e de avaliação utilizados a fim de atingir os objetivos da pesquisa.

\section{Materiais}

\section{Cimento}

A caracterização do cimento Portland IV-32 foi feita seguindo a norma NBR 11548 (ABNT, 1991). As propriedades do material encontram-se na Tabela 1.

\section{Agregados}

Os agregados graúdos e miúdos foram caracterizados utilizando-se as normas NBR NM 53 (ABNT, 2009a) e NBR NM 52 (ABNT, 2009b) respectivamente. Para a determinação da massa unitária, aplicaram-se as especificações da NBR NM 45 (ABNT, 2006). A Tabela 2 mostra as características determinadas para o agregado analisado.

A Tabela 3 apresenta os valores referentes às granulometrias dos agregados selecionados, conforme a NBR NM 248 (ABNT, 2003). Para agregado miúdo utilizou-se areia média. Já para agregado graúdo adotou-se pedrisco com dimensões inferiores a $12,5 \mathrm{~mm}$ e superiores a 4,8 $\mathrm{mm}$.

\section{Fibras}

As fibras utilizadas são de poliéster e direcionadas ao ramo da indústria naval com aplicação em cordas para ancoragem de navios e plataformas petrolíferas. Como seu comportamento mecânico é considerado um fator importante para a segurança dessas embarcações, as questões de durabilidade e desempenho do material são acompanhadas rigorosamente pelo prazo de 15 anos. Após esse período, são postas para descarte sem valores nem aplicabilidade comercial.

A caracterização geométrica e mecânica das fibras utilizadas, tanto novas quanto recicladas, foi obtida através dos dados específicos do fabricante. A Tabela 4 apresenta os parâmetros de caracterização dos reforços.

As dimensões geométricas médias dos filamentos foram obtidas através da submissão de três exemplares de cada tipo de fibra na análise dimensional. As fibras novas obtiveram diâmetro médio de $28,84 \mu \mathrm{m}$ e desvio padrão equivalente a $0,64 \mu \mathrm{m}$. Já as fibras recicladas de poliéster foram caracterizadas com diâmetro médio de 30,25 $\mu \mathrm{m}$ e desvio padrão de $0,70 \mu \mathrm{m}$. Nos ensaios de caracterização geométrica utilizou-se microscópio eletrônico de varredura fabricado pela Zeiss, modelo EVO MA10, com potencial de aproximação equivalente a 106 vezes. A resolução espacial máxima do equipamento é de $2 \mathrm{~nm}$. A Figura 1 apresenta a característica física das fibras novas e recicladas de poliéster quando vistas a olho nu. Ambas as fibras possuem comprimento de $40 \mathrm{~mm}$.

Tabela 1 - Caracterização do aglomerante

\begin{tabular}{c|c|c}
\hline Massa específica & Massa unitária & Teor de pozolana \\
\hline $2,81 \mathrm{~g} / \mathrm{cm}^{3}$ & $1,12 \mathrm{~g} / \mathrm{cm}^{3}$ & $33 \%$ \\
\hline
\end{tabular}


Tabela 2 - Caracterização dos agregados

\begin{tabular}{c|c|c}
\hline Agregado & Massa específica & Massa unitária \\
\hline Graúdo & $2,55 \mathrm{~g} / \mathrm{cm}^{3}$ & $1,20 \mathrm{~g} / \mathrm{cm}^{3}$ \\
Miúdo & $2,60 \mathrm{~g} / \mathrm{cm}^{3}$ & $1,49 \mathrm{~g} / \mathrm{cm}^{3}$ \\
\hline
\end{tabular}

Tabela 3 - Composição granulométrica dos agregados

\begin{tabular}{|c|c|c|c|c|}
\hline \multirow[b]{2}{*}{$\begin{array}{c}\text { Peneira } \\
\text { (mm) }\end{array}$} & \multicolumn{2}{|r|}{ Areia } & \multicolumn{2}{|c|}{ Pedrisco } \\
\hline & $\begin{array}{c}\text { Retida } \\
\text { (\%) }\end{array}$ & $\begin{array}{c}\text { Acumulada } \\
(\%)\end{array}$ & $\begin{array}{c}\text { Retido } \\
\text { (\%) }\end{array}$ & $\begin{array}{c}\text { Acumulado } \\
(\%)\end{array}$ \\
\hline 12,5 & 0 & 0 & 0 & 0 \\
\hline 9,5 & 0 & 0 & 0,6 & 0,6 \\
\hline 6,3 & 0 & 0 & 29,1 & 29,7 \\
\hline 4,8 & 1 & 1 & 62,4 & 100 \\
\hline 2,4 & 3 & 4 & 0 & 100 \\
\hline 1,2 & 8 & 12 & 0 & 100 \\
\hline 0,6 & 12 & 24 & 0 & 100 \\
\hline 0,3 & 37 & 61 & 0 & 100 \\
\hline 0,15 & 36 & 97 & 0 & 100 \\
\hline Fundo $(<0,15)$ & 3 & 100 & 0 & 100 \\
\hline Módulo de finura & \multicolumn{2}{|r|}{1,99} & \multicolumn{2}{|r|}{6,01} \\
\hline Dimensão máxima & \multicolumn{2}{|c|}{$4,8 \mathrm{~mm}$} & \multicolumn{2}{|c|}{$9,5 \mathrm{~mm}$} \\
\hline
\end{tabular}

Tabela 4 - Composição das fibras utilizadas

\begin{tabular}{c|c|c|c|c}
\hline Filamentos & Material & Tração & $\begin{array}{c}\text { Módulo de } \\
\text { elasticidade }\end{array}$ & $\begin{array}{c}\text { Massa } \\
\text { específica }\end{array}$ \\
\cline { 1 - 5 } Fibra nova & Poliéster & $687 \mathrm{MPa}$ & $8 \mathrm{GPa}$ & $1,41 \mathrm{~g} / \mathrm{cm}^{3}$ \\
\cline { 1 - 2 } & Fibra reciclada & $1,36 \mathrm{~g} / \mathrm{cm}^{3}$ \\
\hline
\end{tabular}

Fonte: adaptado de Cordoaria São Leopoldo (2017).

Figura 1 - Fibra nova de poliéster com comprimento de $40 \mathrm{~mm}$

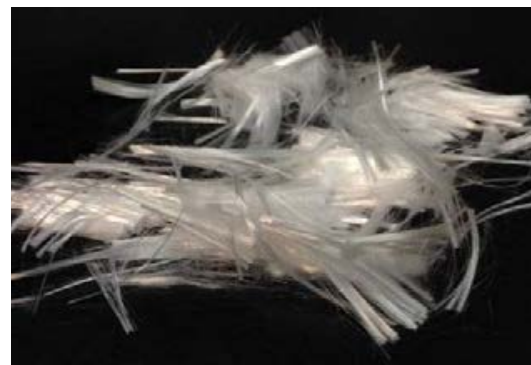

(a) Fibras novas

Conforme visto na Figura 1, nota-se que não há diferenciação entre as fibras quando analisadas sem equipamentos ópticos especiais. Todavia, para facilitar a visualização das características físicas inerentes de cada reforço, utilizou-se a técnica de microscopia eletrônica de varredura (MEV), ampliando em 500 vezes a imagem exposta na figura acima. A Figura 2 apresenta os resultados quando as imagens são ampliadas.

Observa-se que microscopicamente os filamentos possuem conformações superficiais distintas, sendo

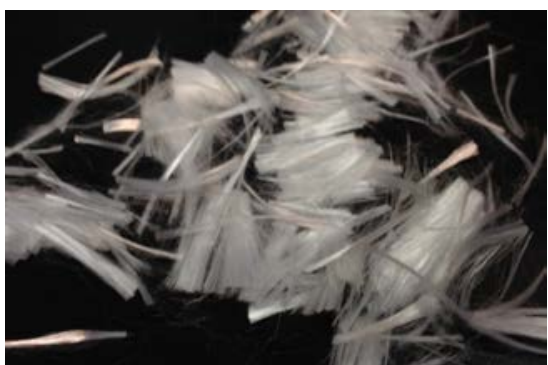

(b) Fibras recicladas

as fibras novas lisas, e as recicladas irregulares. As diferenças podem ser explicadas pelas condições de exposição de cada material. As fibras recicladas passaram por estresse mecânico, por meio de carregamentos, gerando esforços de tração, os quais são os principais fatores relacionados com a mudança física delas. Dessa forma, tendo a conformação física, as fibras recicladas possuem maior área superficial, o que melhora a interação fibra-matriz pelo aumento do fator de atrito. 
Figura 2 - Ilustração da superfície das amostras de fibras novas (A) e recicladas (B)

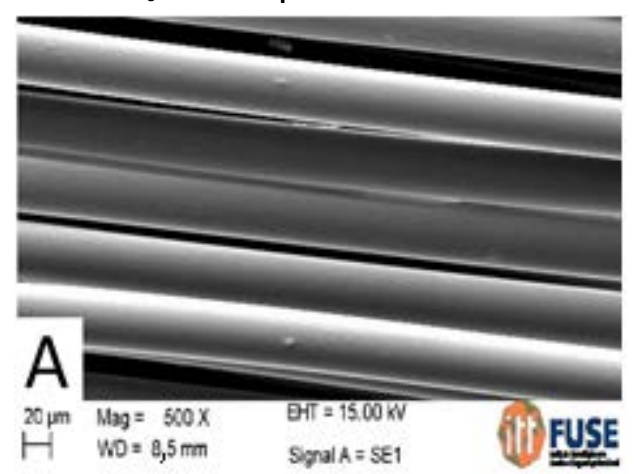

\section{Ensaios}

A seção a seguir apresenta os ensaios propostos para a realização dos experimentos nas amostras da pesquisa.

\section{Resistência à compressão axial}

Para o ensaio de resistência à compressão axial das amostras, utilizou-se uma prensa hidráulica com capacidade de $2.000 \mathrm{kN}$. A velocidade de aplicação de carga foi de $0,45 \mathrm{MPa} / \mathrm{s}$. As idades ensaiadas foram de 7 e 28 dias, sendo ensaiados dois corpos de prova por idade, totalizando oito exemplares. O ensaio seguiu os procedimentos da NBR 5739 (ABNT, 2007).

\section{Ensaio de retração restringida}

O ensaio de anel, ou Ring Test, é descrito pela ASTM C1581 (AMERICAN..., 2009). Esse ensaio caracteriza as propriedades do concreto em relação ao seu potencial de fissuração por retração restringida devido à tensão de compressão exercida pelo anel de concreto sobre o núcleo de aço. No processo de secagem do concreto tensões de compressão são criadas sobre núcleo, oriundas da movimentação da mistura, ocasionando a solicitação da forma interna metálica. A Figura 3 mostra o procedimento de ensaio, com posicionamento dos extensômetros para medição das tensões.

A medição dessas tensões é feita utilizando-se um sistema de aquisição de dados que capta os valores dos pulsos elétricos emitidos aos extensômetros colados na face interna dos núcleos metálicos e converte-os em valores numéricos. De acordo com a C1581 (AMERICAN..., 2009), os extensômetros devem ser fixados a meia altura da face interna do núcleo metálico (Figura 4), tendo em cada molde a instalação de no mínimo duas unidades para medição.

A duração do ensaio de retração por secagem pelo método do anel restringido, segundo a C1581

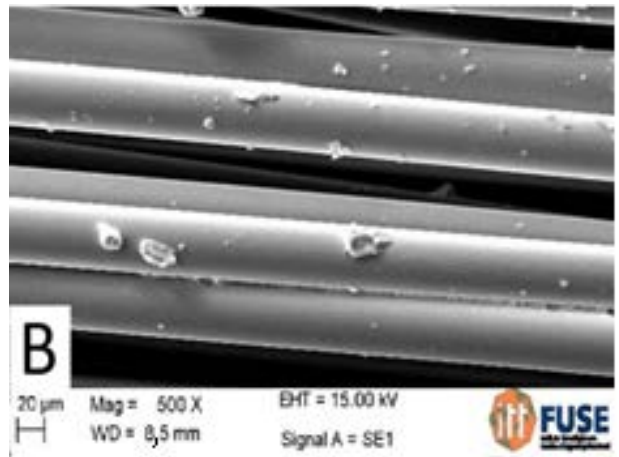

(AMERICAN..., 2009), deve ser de no máximo 28 dias. Os testes são encerrados no momento em que há a constatação da formação da fissura no compósito. Todavia, caso a fissuração não ocorra dentro dos 28 dias de idade, as análises são feitas tomando-se como base as deformações de cada elemento.

Os ensaios ocorreram em uma sala climatizada, com temperatura e umidade controladas, conforme estipula a C1581 (AMERICAN..., 2009). A temperatura e a umidade do ambiente de ensaio permaneceram, respectivamente, em $23 \pm 2{ }^{\circ} \mathrm{C}$ e $50 \pm 4 \%$.

Para cada tipo de concreto foram produzidas duas amostras, denominadas CR 1 e CR 2 (concreto de referência), CFN 1 e CFN 2 (concreto reforçado com fibras novas de poliéster) e CFU 1 e CFU 2 (concreto reforçado com fibras recicladas de poliéster).

\section{Mistura e moldagem de amostras}

A confecção dos concretos seguiu o método de dosagem proposto por Tutikian e Helene (2011), com a relação água-cimento de 0,60 e traço unitário de 1,0: 2,0: 2,5 (cimento: areia: brita), em massa. A mistura foi composta com teor de argamassa de $55 \%$ e contou com a adição de fibras de poliéster no teor de $0,30 \%$ do volume total de concreto utilizado em cada amostra.

A mistura dos materiais foi feita em uma betoneira de eixo vertical, sendo posto o agregado graúdo inicialmente; depois, o cimento e metade da quantidade de água da mistura. Em seguida, adicionaram-se a areia e a quantidade de água restante para o traço. Por fim, adicionaram-se as fibras de maneira aleatória e manualmente.

A moldagem dos corpos de prova para o ensaio de compressão axial foi realizada conforme especifica a norma NBR 5738 (ABNT, 2015). Já para os anéis metálicos seguiu-se a C1581 (AMERICAN..., 2009), conforme a Figura 5. 
Figura 3 - Instrumentação do sistema de aquisição de dados para a execução do ensaio de retração

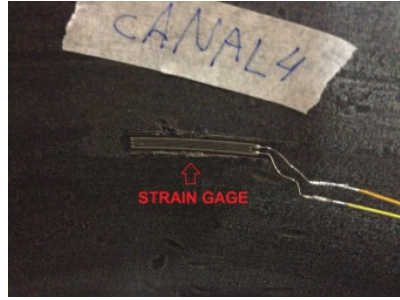

(a)

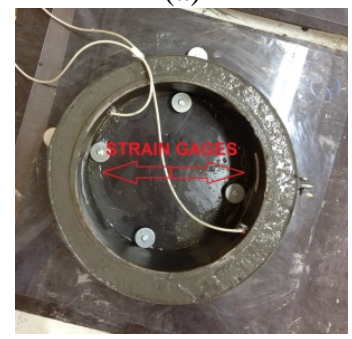

(c)

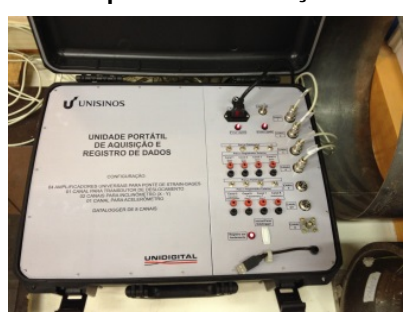

(b)

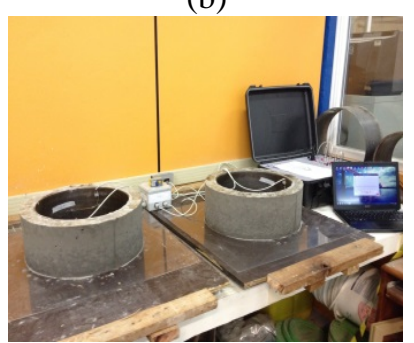

(d)

Nota: Legenda:

(A) Ponto de medição no núcleo metálico;

(B) sistema de aquisição de dados;

(C) disposição dos pontos de medida; e

(D) instrumentação completa do ensaio de retração restringida.

Figura 4 - Colagem e posicionamento dos extensômetros elétricos

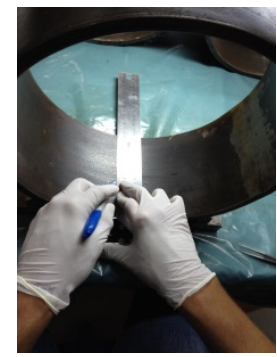

(a)

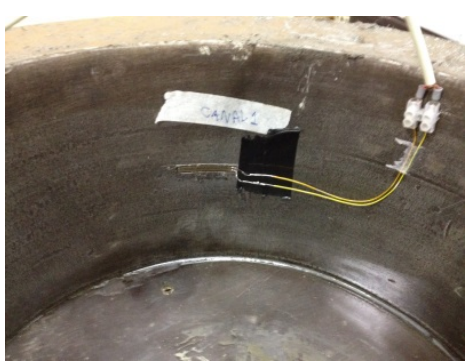

(b)

Nota: Legenda:

(A) Marcação do eixo da altura do núcleo metálico; e

(B) ponto de medição em funcionamento.

Figura 5 - Dimensões dos moldes para o ensaio do anel
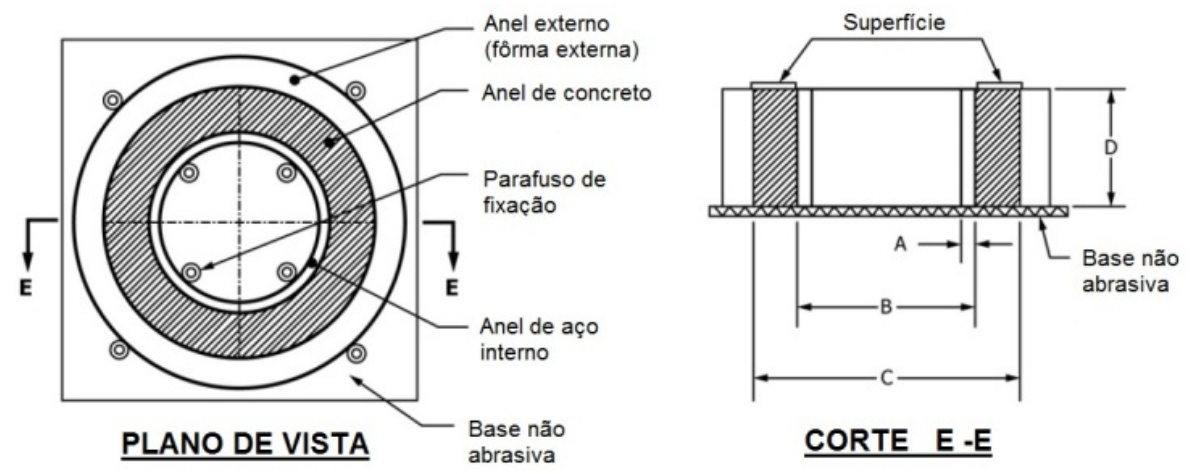

\begin{tabular}{c|c}
\hline Seção & Dimensões \\
\hline A & $13 \pm 1 \mathrm{~mm}$ \\
B & $330 \pm 3 \mathrm{~mm}$ \\
C & $405 \pm 3 \mathrm{~mm}$ \\
D & $150 \pm 6 \mathrm{~mm}$ \\
\hline
\end{tabular}

Fonte: C1581 (AMERICAN..., 2009). 
O adensamento da mistura foi feito em duas camadas. Para cada camada foram aplicados 75 golpes com uma haste metálica de diâmetro igual a $10 \mathrm{~mm}$. Ao final do adensamento regularizou-se a superfície da amostra, retirando-se qualquer excesso de material do interior do anel e ao longo da circunferência externa da amostra, conforme mostra a Figura 6.

\section{Resultados}

A seguir são apresentados os resultados para as misturas analisadas.

\section{Retração por secagem restringida (ensaio de anel)}

\section{Concreto de referência}

Os resultados de retração por secagem do concreto de referência podem ser observados na Figura 7. Os valores são referentes às deformações médias diárias em cada exemplar concretado.

As curvas de deformação das amostras do concreto de referência apresentam-se semelhantes até os 15 dias de ensaio. Verifica-se que os picos de tensão permanecem na faixa de 70 a $80 \mathrm{~N} / \mathrm{cm}^{2}$, obtendo um alívio brusco no $15^{\circ}$ dia. Após esse período as tensões remanescentes tendem a se estabilizar próximo à tensão nula. Durante os testes nota-se que as tensões aumentam ao longo do tempo. $\mathrm{O}$ aumento da magnitude das tensões é proporcionado pela contração do anel de concreto, visto que permanece no período de cura, ou seja, no processo de hidratação dos grãos de cimento. Dessa forma, a medida que aumentam as contrações, os esforços internos elevam-se, pelo fato de haver restrição na movimentação do composto.

Figura 6 - Procedimento de moldagem dos corpos de prova para o ensaio de anel

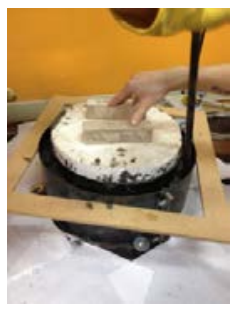

(a)

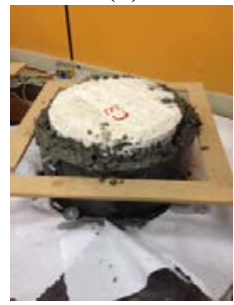

(c)

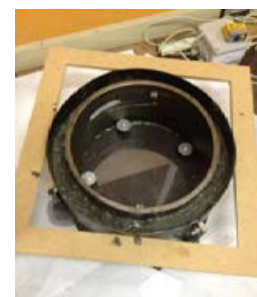

(b)

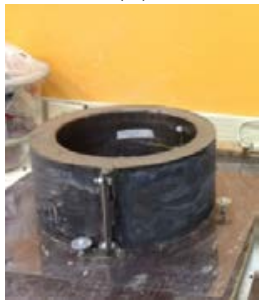

(d)

Nota: Legenda:
(A) adensamento manual da primeira camada;
(B) primeira camada adensada;
(C) segunda camada adensada; e
(D) regularização da superfície e limpeza da base e dos moldes para iniciar o ensaio.

Figura 7 - Tensão média diária dos strain gages nos núcleos metálicos das amostras do concreto de referência

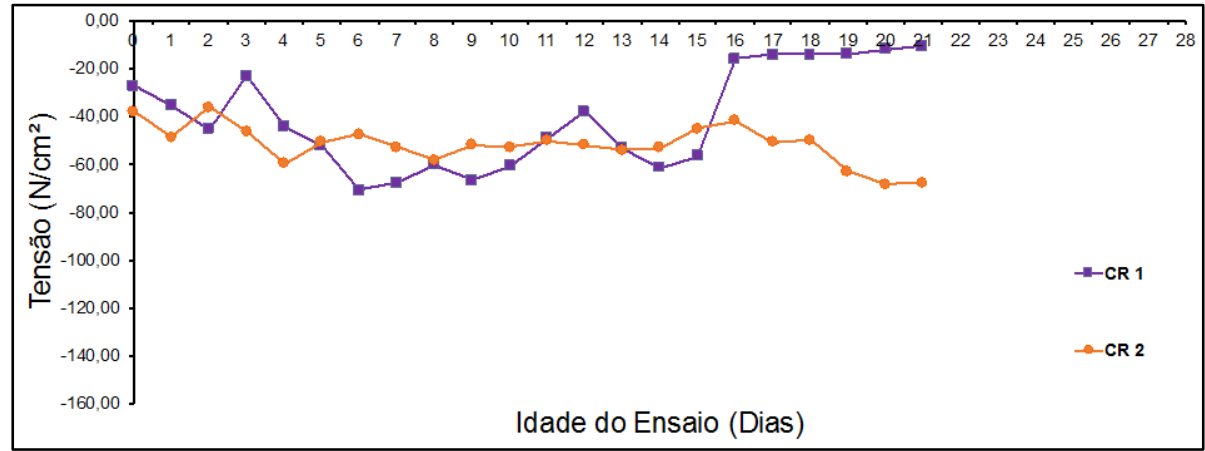


Segundo Mokarem, Weyers e Lane (2005), os alívios de tensão retratam o momento em que as tensões acumuladas no compósito, em virtude da diminuição de volume e da restrição de movimento imposta pelo núcleo metálico, se dispersam por abertura. Assim, visto que o alívio de tensões ocorre bruscamente no período entre 14 e 16 dias, é possível identificar instrumentalmente a nucleação de fissura na matriz. A constatação visual da fissura ocorreu aos 17 dias de ensaio, ou seja, 2 dias após a identificação pelo método instrumentado.

Tal comportamento expressa a deficiência da matriz quando submetida aos esforços de tração. A matriz é fragilizada e não possui recursos para combater a propagação das fissuras geradas. Esse princípio é verificado na pesquisa realizada por Figueiredo (2000), a qual verifica o acúmulo de tensões na extremidade dessas aberturas, fazendo com que elas se propaguem facilmente em uma matriz cimentícia não reforçada.

A Figura 8 representa a formação das fissuras nas amostras do concreto de referência e ilustra a dimensão das fissuras.

As dimensões das fissuras encontradas nos exemplares foram mensuradas durante 4 dias após a constatação visual da anomalia, as quais são apresentadas na Tabela 5.

\section{Concreto reforçado com fibras novas de poliéster}

A Figura 9 representa os resultados obtidos no ensaio de retração restringida por secagem em concretos com adição de fibras novas de poliéster. Nela estão expressos os valores das tensões médias diárias em cada amostra ensaiada durante o intervalo de 21 dias.

Nas idades iniciais do ensaio, nota-se que o desenvolvimento das tensões apresenta constância nos valores anormais quando comparado ao restante do diagrama. É comum haver variações no decorrer do ensaio, as quais podem ser observadas após o $4^{\circ}$ dia. Ao longo do ensaio as reações de hidratação da pasta de cimento se intensificam, e, consequentemente, os esforços sobre o núcleo metálico também, atingindo a marca de 150 N/cm². Comparando ao concreto referência, a inserção de fibras novas de poliéster provocou aumento de quase $100 \%$ das tensões de retração, todavia nessas circunstâncias o compósito apresentou maior capacidade de absorção de tensões.

\section{Figura 8 - Fissuração da amostra CR 1 do concreto de referência}

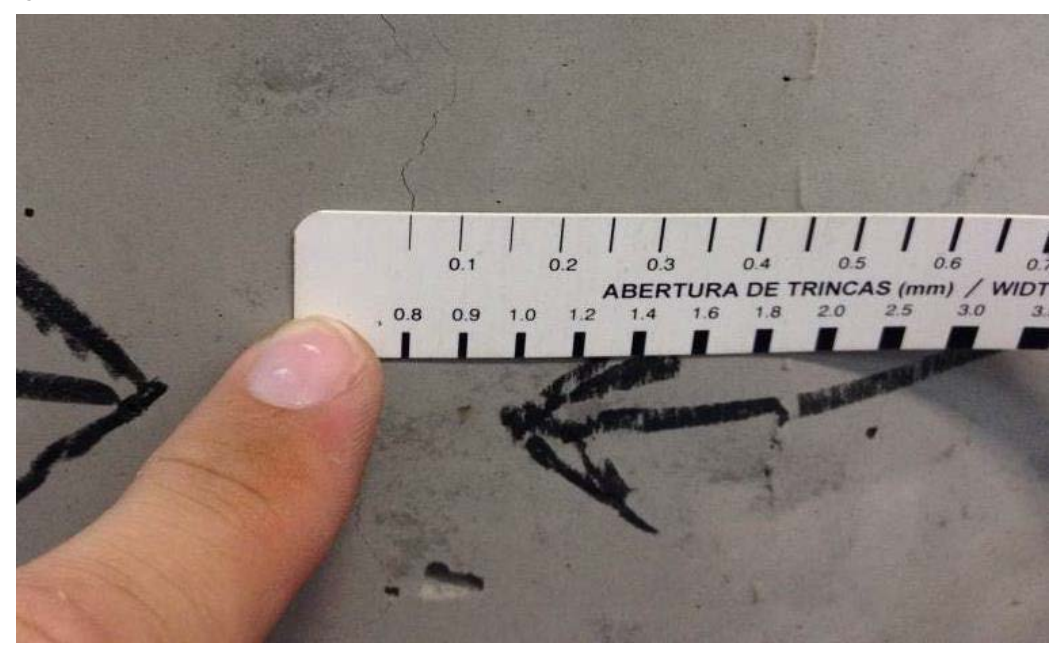

Tabela 5 - Dimensão das aberturas nas amostras de concreto com fibras de poliéster novas

\begin{tabular}{c|c|c|c|c|c}
\hline \multirow{2}{*}{ Amostra } & \multirow{2}{*}{ Fissura } & \multicolumn{4}{|c}{ Medições (dias) - mm } \\
\cline { 3 - 6 } & & $\mathbf{1}^{\mathbf{0}}$ & $\mathbf{2}^{\mathbf{0}}$ & $\mathbf{3}^{\mathbf{0}}$ & $\mathbf{4}^{\mathbf{0}}$ \\
\hline \multirow{2}{*}{ CR 1 } & $1^{\mathrm{a}}$ & $<0,05$ & 0,05 & 0,05 & 0,05 \\
& $2^{\mathrm{a}}$ & 0,05 & 0,05 & 0,05 & 0,05 \\
\hline CR 2 & $1^{\mathrm{a}}$ & 0,05 & 0,05 & 0,05 & 0,05 \\
\hline
\end{tabular}


Figura 9 - Tensão média diária dos strain gages nos núcleos metálicos das amostras de concreto com fibras novas de poliéster

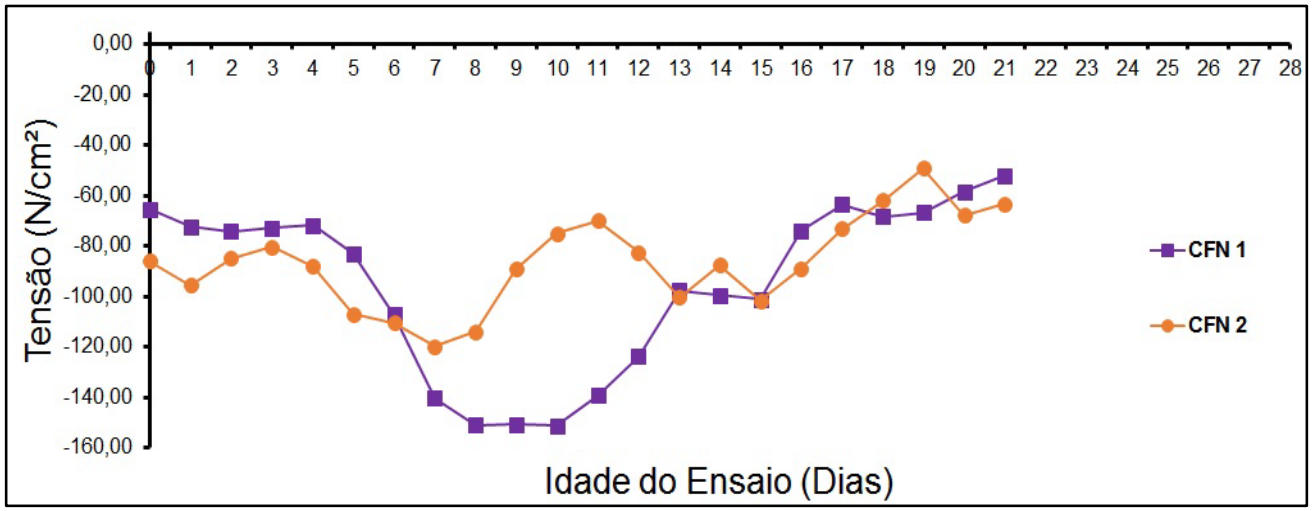

Os picos de tensão ocorrem entre o $7^{\circ}$ e o $9^{\circ}$ dia nas duas amostras analisadas. Nota-se que as ações decorridas nesse intervalo influenciam no comportamento pós-pico das amostras, ocorrendo o alívio das tensões até a estabilização. Em outras palavras, é possível verificar a nucleação de fissuras na amostra nos 7 e 9 dias após a concretagem. O período em que ocorre a diferença de comportamento dos esforços internos do concreto também contempla a disparidade dos alívios de tensão em cada molde.

Com o alívio de tensão os esforços tendem a diminuir sua módulo, assim como é expresso no gráfico de tensões de cada amostra ensaiada. Notase que o comportamento das tensões se torna congênere a partir do $13^{\circ}$ dia até o encerramento dos ensaios. Entretanto, após a formação da primeira fissura, mesmo com a diminuição da tensão interna no material, ela tenderá a se propagar. O estágio pós-pico denota que as tensões são aliviadas mesmo ainda havendo a retração da matriz ao longo dos dias, conforme a Figura 9. Nesse caso, é pertinente verificar a ocorrência da propagação da fissura ou sua contenção com o uso do reforço fibroso.

Aos 15 dias de ensaio comprovou-se visualmente na amostra CFN 1 a formação da primeira fissura e posteriormente o alívio de tensões suavizados, ao contrário do que ocorreu no concreto de referência. Já a constatação de fissuras na amostra CFN 2 ocorreu aos 18 dias de ensaio. O período entre o alívio de tensão e a constatação da abertura define a eficiência da fibra adicionada no composto, visto que o filamento só é acionado após a fragilização da matriz. Nesse caso, as fibras novas de poliéster foram eficientes por um período médio de 4 dias, em que o composto, segundo a norma C1581 (AMERICAN..., 2009), em função dos resultados apresentados, é classificado com um potencial moderado-alto de fissuração. Para essa classificação adotaram-se os parâmetros relacionados à deformação máxima do concreto e o dia da constatação da primeira fissura.

A espessura da fissura na amostra CFN 1 mantevese com dimensões inferiores a $0,05 \mathrm{~mm}$, como se observa na Figura 10 . No $19^{\circ}$ dia de ensaio ocorreu a formação da segunda fissura na mesma amostra. Já no molde denominado de CFN 2 duas fissuras foram contatadas visualmente aos 18 dias de ensaio.

A Tabela 6 mostra a dimensão das fissuras observadas no concreto com fibras novas de poliéster.

\section{Concreto reforçado com fibras recicladas de poliéster}

A Figura 11 ilustra as tensões médias geradas pelo concreto reforçado com fibras recicladas de poliéster. Foi obtido com os valores médios diários obtidos a partir da coleta feita pelo sistema de aquisição de dados. O método de cálculo utilizado para determinação das tensões médias foi o mesmo do adotado com as amostras com fibras novas.

No concreto com fibras recicladas, no período inicial, mais precisamente no $6^{\circ}$ dia, as tensões em cada núcleo possuem comportamentos distintos, voltando à normalidade apenas na etapa final Mesmo com a diferença dos resultados, as tensões atuantes nos núcleos metálicos não obtiveram picos expressivos, mantendo ações comportadas, com exceção dos valores entre o período do $19^{\circ}$ ao $21^{\circ}$ dia. As intensidades das tensões foram próximas às atingidas no CFN, todavia ainda foram superiores às do concreto de referência. Dessa maneira, também é possível verificar o melhoramento no comportamento mecânico do compósito quando se aumentam as tensões de confinamento, suportando esforços mais elevados sem ocorrer a fragilização. 
Figura 10 - Fissuração da amostra CFN 1 do concreto reforçado com fibras novas de poliéster

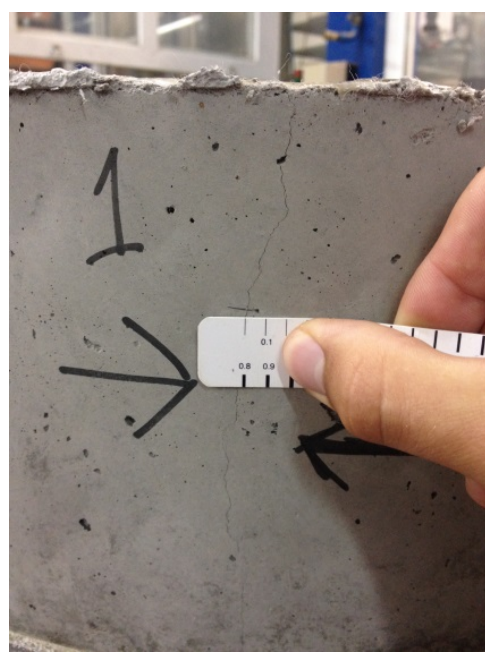

(a)

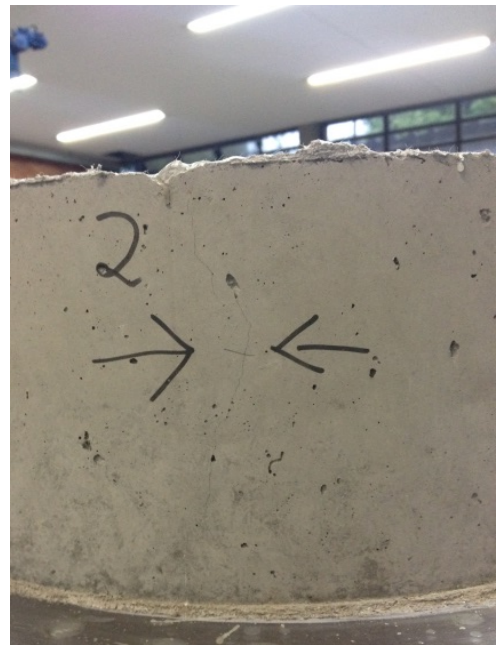

(b)

Nota: Legenda:

(A) Medição da primeira fissura aos 21 dias; e

(B) segunda fissura originada na amostra.

Tabela 6 - Dimensão das aberturas nas amostras de concreto com fibras de poliéster novas

\begin{tabular}{c|c|c|c|c|c}
\hline \multirow{2}{*}{ Amostra } & \multirow{2}{*}{ Fissura } & \multicolumn{4}{|c}{ Medições (dias) - mm } \\
\cline { 3 - 6 } & & $\mathbf{1}^{\mathbf{0}}$ & $\mathbf{2}^{\mathbf{0}}$ & $\mathbf{3}^{\mathbf{0}}$ & $\mathbf{4}^{\mathbf{0}}$ \\
\hline \multirow{2}{*}{ CFN 1 } & $1^{\mathrm{a}}$ & $<0,05$ & 0,05 & 0,05 & 0,05 \\
& $2^{\mathrm{a}}$ & $<0,05$ & $<0,05$ & 0,05 & - \\
\hline \multirow{2}{*}{ CFN 2 } & $1^{\mathrm{a}}$ & $<0,05$ & 0,05 & 0,05 & - \\
& $2^{\mathrm{a}}$ & $<0,05$ & $<0,05$ & - & - \\
\hline
\end{tabular}

Figura 11 - Tensão média diária dos strain gages nos núcleos metálicos das amostras de concreto com fibras recicladas de poliéster

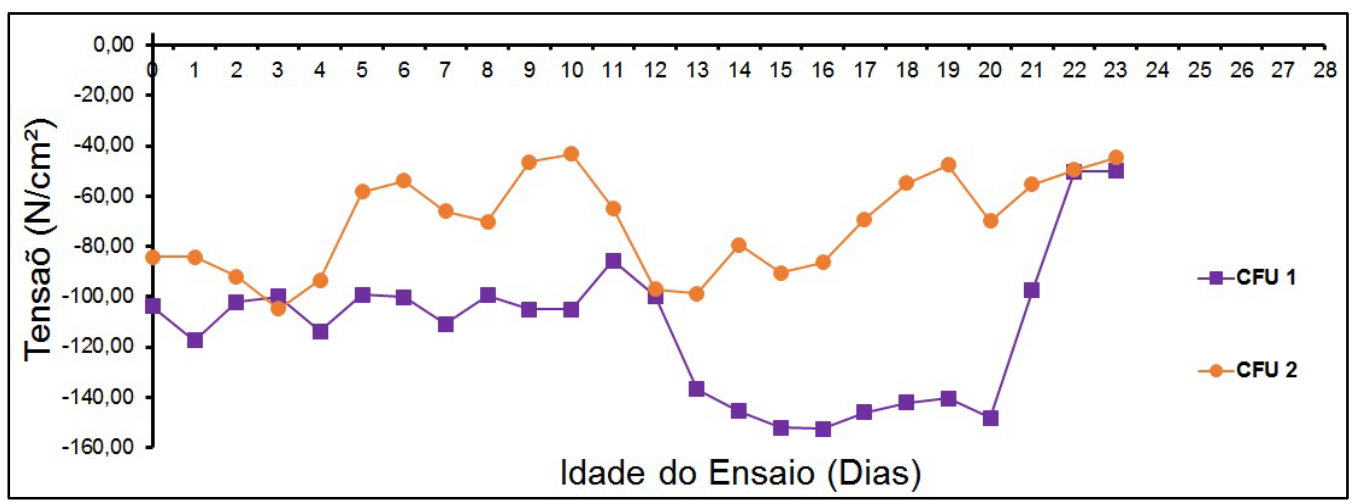

A evolução dos esforços é gradual, com o alívio das tensões ocorrendo aos 20 dias. Como ilustram as curvas apresentadas na Figura 11, é possível perceber um alívio das tensões no $13^{\circ}$ e no $20^{\circ}$ dia de ensaio. A partir desse indicativo, constata-se que a adição das fibras recicladas de poliéster permitiu retardar o surgimento e a propagação das fissuras, quando comparado às curvas obtidas com o reforço de fibras novas.
Associadas ao alívio de tensões do $13^{\circ}$ dia, as primeiras fissuras surgiram aos 20 dias de ensaio nas amostras CFU 1 e CFU 2 (Figura 12). Ambas as amostras manifestaram indícios de fissuração no mesmo dia. O acompanhamento das fissuras nas amostras CFU 1 e CFU 2 ocorreu durante o $20^{\circ}$, o $21^{\circ}$, o $22^{\circ}$ e o $23^{\circ}$ dia de ensaio, assim mostrado na Tabela 7.

Diferentemente do concreto com fibras novas de poliéster e o concreto de referência, as amostras do 
concreto reforçado com fibras recicladas de poliéster obtiveram resultados melhores no que se diz respeito à eficiência dos filamentos. As fibras recicladas de poliéster foram eficientes por um período de 7 dias, valor 1,75 vez maior em função do resultado encontrado para as fibras novas. Segundo a norma C1581 (AMERICAN..., 2009), de acordo com os resultados apresentados, é classificado com um potencial moderado-baixo de fissuração.

Comparando o comportamento da matriz sem reforço com o da matriz com reforço, o comportamento mecânico e a forma de ruptura foram modificados. Ao fissurar, o concreto de referência apresentou alívio repentino das tensões, ou seja, ruptura frágil. Já nos concretos com fibras o alívio de tensões foi mais suave, evitando a propagação brusca da fissura. No caso de contenção das fissuras, as fibras recicladas redistribuíram e suportaram temporariamente as tensões geradas sobre o núcleo metálico, fazendo com que a primeira abertura fosse averiguada apenas aos 20 dias de ensaio. Contudo, não foi possível evitar, com maior eficácia, a propagação da abertura das fissuras, igualando-se as dimensões geométricas encontradas nas amostras de fibras novas.

\section{Ensaio de resistência à compressão axial}

Os resultados de resistência à compressão axial dos concretos com fibras são apresentados na Tabela 8.

Verifica-se que a resistência à compressão do concreto de referência não é modificada em função da adição de $0,30 \%$ de fibras novas ou recicladas de poliéster. $\mathrm{O}$ comportamento mecânico desses materiais tanto aos 7 dias quanto aos 28 dias é semelhante, não havendo prejuízos ante a adição.

Figura 12 - Fissuração da amostra CFU 1 do concreto reforçado com fibras de poliéster recicladas

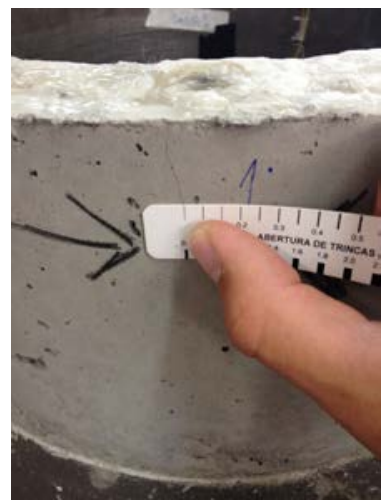

(a)

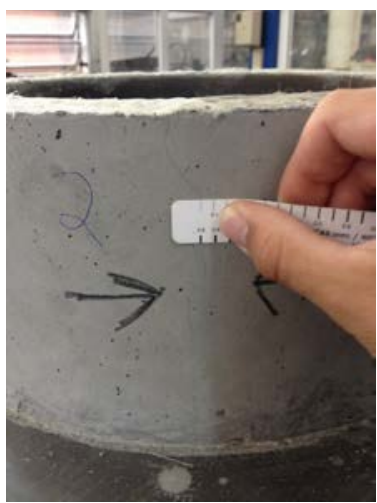

(b)

Nota: Legenda:

(A) Quantificação geométrica da primeira fissura da amostra aos 20 dias; e

(B) segunda fissura originada na amostra e identificada aos 21 dias de ensaio.

Tabela 7 - Dimensão das aberturas nas amostras de concreto com fibras de poliéster recicladas

\begin{tabular}{c|c|c|c|c|c}
\hline \multirow{2}{*}{ Amostra } & \multirow{2}{*}{ Fissura } & \multicolumn{4}{|c}{ Medições (dias) - mm } \\
\cline { 3 - 6 } & & $\mathbf{1}^{\mathbf{0}}$ & $\mathbf{2}^{\mathbf{0}}$ & $\mathbf{3}^{\mathbf{0}}$ & $\mathbf{4}^{\mathbf{0}}$ \\
\hline \multirow{2}{*}{ CFU 1 } & $1^{\mathrm{a}}$ & $<0,05$ & $<0,05$ & $<0,05$ & $<0,05$ \\
& $2^{\mathrm{a}}$ & 0,05 & 0,05 & 0,05 & 0,05 \\
\hline \multirow{2}{*}{ CFU 2 } & $1^{\mathrm{a}}$ & $<0,05$ & $<0,05$ & $<0,05$ & $<0,05$ \\
& $2^{\mathrm{a}}$ & 0,05 & 0,05 & 0,05 & 0,05 \\
\hline
\end{tabular}

Tabela 8 - Resistência à compressão axial das misturas analisadas

\begin{tabular}{c|c|c|c|c}
\hline \multirow{2}{*}{ Composto } & \multirow{2}{*}{ Amostras } & \multicolumn{3}{|c}{ Resistência à compressão (MPa) } \\
\cline { 3 - 5 } & & $\mathbf{7}$ dias & $\mathbf{2 8}$ dias & Potencial \\
\hline \multirow{2}{*}{ CR } & CR 1 & 15,6 & 25,0 & \multirow{2}{*}{26,4} \\
& CR 2 & 16,5 & 26,4 & \\
\hline \multirow{2}{*}{ CFN } & CFN 1 & 17,4 & 26,2 & \multirow{2}{*}{26,6} \\
& CFN 2 & 16,3 & 26,6 & 25,5 \\
\hline \multirow{2}{*}{ CFU } & CFU 1 & 16,3 & 24,9 & \multirow{2}{*}{} \\
& CFU 2 & 15,6 & 25,5 & \\
\hline
\end{tabular}




\section{Conclusão}

Com base nos resultados apresentados é possível verificar que as tensões de retração por secagem de uma matriz de concreto são intensificadas com a inserção de filamentos em poliéster. Além desse, verifica-se que a inclusão desses reforços não afeta a resistência à compressão axial da mistura quando se trabalha com teores de $0,30 \%$. O comportamento pós-fissuração também é alterado, sendo que os CRF apresentam alívio suave, e o concreto de referência, alívio brusco.

Os resultados encontrados para os concretos com adição de fibras recicladas de poliéster são superiores aos obtidos nos ensaios do concreto com fibras novas de poliéster. A idade da primeira fissura, a deformação tangencial, o potencial de fissuração e a distribuição das tensões obtiveram ganhos no momento em que o concreto recebeu as fibras recicladas. Possuindo eficiência 1,75 vez maior do que as fibras novas, as fibras recicladas absorveram por mais tempo a ação das tensões sobre o compósito. Além destes, a classificação do material foi alterada, passando para um potencial moderado-baixo em função de fissuras ocorridas pela retração.

Os compósitos com fibras novas mostrou-se mais deformável em relação ao com fibras recicladas, porém se constataram fissuras precoces devido à alta concentração de tensões internas. As maiores tensões no CFN ocorreram nos primeiros dias, período em que a resistência e o módulo de elasticidade do material ainda são baixos. No CFU o aumento das tensões acontece muito próximo aos 21 dias de ensaio, idade em que o material já garante maior resistência de absorção dos esforços de tração.

Comparando microscopicamente os filamentos pelo ensaio de microscopia eletrônica de varredura (MEV), nota-se que as fibras recicladas possuem maior área superficial quando comparadas às fibras novas. Essa dessemelhança é atrelada à modificação da conformação da superfície das fibras recicladas, as quais puderam ser observadas ao longo dos resultados. Com esse fator, a interação fibra-matriz nas fibras recicladas é mais eficiente, o que promove melhor ancoragem com a pasta cimentícia e, por sua vez, atinge melhor comportamento físico e mecânico para conter a nucleação de fissuras formadas por meio da retração por secagem restringida.

\section{Referências}

ABABNEH, A. M. The Damage of Concrete Structures Due to Coupled Moisture Transfer and Drying Shrinkage. In: ASCE STRUCTURES CONGRESS AND EXPOSITION, Washington, 2001. Proceedings... Washington, 2001.

ALKAYSI, M. et al. Effects of Silica Powder and Cement Type on Durability of Ultra-High Performance Concrete (UHPC). Cement and Concrete Composites, v. 66, p. 47-56, 2015.

AMERICAN SOCIETY FOR TESTING AND MATERIALS. ASTM C1581: standard test method for determining age at cracking and induced tensile stress characteristics of mortar and concrete under restrained shrinkage. Pennsylvania, 2009.

\section{ASSOCIAÇÃO BRASILEIRA DE NORMAS} TÉCNICAS. NBR 11548: cimento Portland composto: especificação. Rio de Janeiro, 1991.

ASSOCIAÇÃO BRASILEIRA DE NORMAS TÉCNICAS. NBR 5738: concreto: procedimento para moldagem e cura de corpos de prova. Rio de Janeiro, 2015.

ASSOCIAÇÃO BRASILEIRA DE NORMAS TÉCNICAS. NBR 5739: concreto: ensaios de compressão de corpos-de-prova cilíndricos. Rio de Janeiro, 2007.

\section{ASSOCIAÇÃO BRASILEIRA DE NORMAS}

TÉCNICAS. NBR NM 248: agregados: determinação da composição granulométrica. Rio de Janeiro, 2003.

\section{ASSOCIAÇÃO BRASILEIRA DE NORMAS TÉCNICAS. NBR NM 45: agregados: determinação da massa unitária e do volume de vazios. Rio de Janeiro, 2006.}

\section{ASSOCIAÇÃO BRASILEIRA DE NORMAS TÉCNICAS. NBR NM 52: agregado miúdo: determinação da massa específica e massa específica aparente. Rio de Janeiro, 2009b.}

ASSOCIAÇÃO BRASILEIRA DE NORMAS TÉCNICAS. NBR NM 53: agregado graúdo: determinação da massa específica, massa específica aparente e absorção de água. Rio de Janeiro, 2009a.

BENTUR A.; MINDESS, S. Fiber Reinforced Cementitious Composites. New York: Taylor \& Francis, 2007. 
BERNARDI, S. T. Avaliação do Comportamento de Materiais Compósitos de Matrizes Cimentícias Reforçadas Com Fibra de Aramida Kevlar. Porto Alegre, 2003. Dissertação (Mestrado em Engenharia Civil) - Escola de Engenharia, Universidade Federal do Rio Grande do Sul, Porto Alegre, 2003.

BOGHOSSIAN, E.; WEGNER, L. D. Use of Flax Fibres to Reduce Plastic Shrinkage Cracking in Concrete. Cement and Concrete Composites, v. 30, n. 10, p. 929-937, 2008.

BRAS, A. et al. Development of an Injectable Grout For Concrete Repair and Strengthening. Cement and Concrete Composites, v. 37, p. 185195, 2013.

CARINO, N. J.; CLIFTON, J. R. Prediction of Cracking in Reinforced Concrete Structures. Research Laboratory, National Institute of Standards and Technology, 1995.

CARMONA FILHO, A.; CARMONA, T. Fissuração nas Estruturas de Concreto. Boletim Técnico ALCONPAT Internacional, 2013.

CHASIOTI, S. G.; VECCHIO, F. J. Effect of Fiber Hybridization on Basic Mechanical Properties of Concrete. Materials Journal, v. 114, n. 3, p. 375384, 2017.

\section{CORDOARIA SÃO LEOPOLDO. Catálogo}

Cabos e Cordas. Disponível em:

$<$ http://www.csl.com.br/home/painel/arquivos/cata logo_cabos_e_cordas_pdf.pdf $>$. Acesso em: 14 maio 2018.

DESNERCK, P.; LEES, J. M.; MORLEY, C. T. Bond Behaviour of Reinforcing Bars in Cracked Concrete. Construction and Building Materials, v. 94, p. 126-136, 2015.

DJERBI, A.; BONNET, S.; KHELIDJ, A. Influence of Traversing Crack on Chloride Diffusion Into Concrete. Cement and Concrete Research, v. 38, n. 6, p. 877-883, 2008.

FIGUEIREDO, A. D. Concreto Com Fibras de Aço. São Paulo, 2000. Boletin Técnico -Escola Politécnica da Universidade de São Paulo Departamento de Engenharia de Construção, São Paulo, Brasil.

GHUGAL, Y. M.; NAGHATE, S. V. Performance of Extruded Polyester Fiber Reinforced Concrete. Journal of Structural Engineering, v. 43, n. 3, p. 247-257, 2016.

GOODIER, C. I. Development of seLf-

Compacting Concrete. Structures and Buildings, v. 156, n. 4, p. 405-414, nov. 2003.
GU, C.; YE, G.; SUN, W. A Review of the Chloride Transport Properties of Cracked Concrete: experiments and simulations. Journal of Zhejiang University-SCIENCE A, v. 16, n. 2, p. 81-92, feb. 2015.

IBRAHIM, M. A. et al. Effect of Material Constituents on Mechanical and Fracture Mechanics Properties of Ultra-High-Performance Concrete. Materials Journal, v. 114, n. 3, p. 453465, 2017.

JAMERAN, A. et al. Mechanical Properties of Steel-Polypropylene Fibre Reinforced Concrete Under Elevated Temperature. Procedia Engineering, v. 125, p. 818-824, 2015.

JUAREZ, C. A. et al. Comparative Study Between Natural and PVA Fibers to Reduce Plastic Shrinkage Cracking in Cement-Based Composite. Construction and Building Materials, v. 91, p. 164-170, 2015.

KAUFMANN, J.; WINNEFELD, F.; HESSELBARTH, D. Effect of the Addition of Ultrafine Cement and Short Fiber Reinforcement on Shrinkage, Rheological and Mechanical Properties of Portland Cement pastes. Cement and Concrete Composites, v. 26, p. 541-549, 2004.

KURDOWSKI, W. The Chemistry of Cement and Concrete. Amsterdan: Springer, 2014.

MAZZOLI, A.; MONOSI, S.; PLESCIA, E. S. Evaluation of the Early-Age-Shrinkage of Fiber Reinforced Concrete (FRC) Using Image Analysis Methods. Construction and Building Materials, v. 101, p. 596-601, 2015.

MEHTA, P. K.; MONTEIRO, P. J. M. Concreto: microestrutura, propriedades e materiais. São Paulo: IBRACON, 2014.

MOKAREM, D. W.; WEYERS, R. E.; LANE, D. S. Development of a Shrinkage Performance Specifications and Prediction Model Analysis For Supplemental Cementitious Material Concrete Mixtures. Cement and Concrete Research, v. 35, n. 5, p. 918-925, 2005.

NEVILLE, A. M. Properties of Concrete. São Paulo: [s.n.], 1997.

NEVILLE, A. M.; BROOKS, J. J. Concrete Technology. London: Prentice Hall, 2013.

NUNES, N. L.; FIGUEIREDO, A. D. Retração do Concreto de Cimento Portland. Boletim Técnico da Escola Politécnica da USP. Departamento de Engenharia de Construção Civil, 2007. 
OCHI, T.; OKUBO, S.; FUKUI, S. Development of Recycled PET Fiber and Its Application as Concrete-Reinforcing Fiber. Cement and Concrete Composites, v. 29, p. 448-455, 2007.

OSTERTAG, C. P.; BLUNT, J. Effect of Crack Control in Hybrid Fiber Reinforced Concrete Composites on Corrosion Rate of Steel Reinforcing Bars. Seoul: Korea Concrete Institute, 2010.

PELISSER, F. et al. Mechanical Properties of Recycled PET Fibers in Concrete. Materials Research, v. 15, n. 4, p. 679-686, 2012.

QUININO, U. C. M. Investigação Experimental das Propriedades Mecânicas de Compósitos de Concreto Com Adições Híbridas de Fibras. 2015. Porto Alegre, 243 f. Tese (Doutorado em Engenharia Civil) - Programa de Pós-Graduação em Engenharia Civil, Universidade Federal do Rio Grande do Sul, Porto Alegre, 2015.

SENISSE, J. A. D. L. Estudo do Efeito do Agregado Cerâmico Com Diferentes Porosidades no Comportamento Mecânico e de Retração Livre e Restringida de Concretos, Visando o Uso de Resíduos de Construção e Demolição Como Agente de Cura Interna. Porto Alegre, 2015. 297 f. Tese (Doutorado em Engenharia Civil) - Programa de Pós-Graduação em Engenharia Civil, Universidade Federal do Rio Grande do Sul, Porto Alegre, 2015.

SENISSE, J. A. D. L. Influência do Consumo de Água, do Teor de Adição de Microfibras de Polipropileno e do Tipo de Cimento no Fenômeno da Retração Por Secagem em Concretos Empregados em Pisos. Porto Alegre, 2010. 161 f. Dissertação (Mestrado em Engenharia Civil) - Programa de Pós-Graduação em Engenharia Civil, Universidade Federal do Rio Grande do Sul, Porto Alegre, 2010.

SILVA, E. F. Variações Dimensionais em Concretos de Alto Desempenho Contendo Aditivo Redutor de Retração. Igarss, v. 1, p. 1-5, 2007.
TANESI, J.; FIGUEIREDO, A. D. Fissuração Por Retração em Concretos Reforçados Com Fibras de Polipropileno (CRFP). Boletim Técnico da Escola Politécnica da USP. Departamento de Engenharia de Construção Civil, 1999.

TUTIKIAN, B. F.; HELENE, P. Dosagem dos Concretos de Cimento Portland. In: ISAIA, G. Concreto: Ciência e Tecnologia. São Paulo: IBRACON, 2011.

WITTMANN, F. H.; BELTZUNG, F.; ZHAO, T. J. Shrinkage Mechanisms, Crack Formation and Service Life of Reinforced Concrete Structures. International Journal Structures Engineering, v. 1, n. 1, p. 13-28, 2009.

YIN, S. et al. Post-Cracking Performance of Recycled Polypropylene Fibre in Concrete. Construction and Building Materials, v. 101, p. 1069-1077, 2015.

YOUSEFIEH, N. et al. Influence of Fibers on Drying Shrinkage in Restrained Concrete.

Construction and Building Materials, v. 148, p. 833-845, 2017.

YU, R. et al. Impact Resistance of a Sustainable Ultra-High Performance Fibre Reinforced Concrete (UHPFRC) Under Pendulum Impact Loadings. Construction and Building Materials, v. 107, p. 203-215, 2016.

ZACHARY, C. G.; MATTHEW, D. D. Viscoelastic Properties and Drying Stress Extracted From Concrete Ring Tests. Cement and Concrete Composites, v. 33, p. 171-178, 2011.

ZHANG, W.; ZAKARIA, M.; HAMA, Y. Influence of Aggregate Materials Characteristics on the Drying Shrinkage Properties of Mortar and Concrete. Construction and Building Materials, v. 49, p. 500-510, 2013. 


\section{Hinoel Zamis Ehrenbring}

itt Performance | Universidade do Vale do Rio dos Sinos | Av. Unisinos, 950 | São Leopoldo - RS - Brasil | CEP 93022-750 | Tel.: (51) 35908887 | E-mail: hzamis@unisinos.br

\section{Bernardo Fonseca Tutikian}

Programa de Pós-Graduação em Engenharia Civil, Mestrado Profissional em Arquitetura e Urbanismo | itt Performance | Universidade do Vale do Rio dos Sinos | Tel.: (51) 3590-8887 | E-mail: bftutikian@unisinos.br

\section{Uziel Cavalcanti de Medeiros Quinino}

itt Performance | Universidade do Vale do Rio dos Sinos | Tel.: (51) 3590-8887 | E-mail: uquinino@unisinos.br

Revista Ambiente Construído

Associação Nacional de Tecnologia do Ambiente Construído

Av. Osvaldo Aranha, 99 - 30 andar, Centro

Porto Alegre - RS - Brasil

CEP 90035-190

Telefone: +55 (51) 3308-4084

Fax: +55 (51) 3308-4054

www. seer. ufrgs. br/ ambienteconstruido

E-mail: ambienteconstruido@ufrgs.br

(c) () 